Check for updates

Cite this: RSC Adv., 2019, 9, 11722

Received 25th October 2018

Accepted 25th March 2019

DOI: $10.1039 / c 8 r a 08828 d$

rsc.li/rsc-advances

\title{
Polydopamine-modified poly(L-lactic acid) nanofiber scaffolds immobilized with an osteogenic growth peptide for bone tissue regeneration
}

\author{
Yong Liu, ${ }^{\text {ab }}$ Changlu Xu, ae Yong Gu, ${ }^{a}$ Xiaofeng Shen, ${ }^{c}$ Yanxia Zhang, ${ }^{d}$ Bin Li ${ }^{\mathrm{e}}$ \\ and Liang Chen (D) *a
}

It is highly desirable for bone tissue engineering scaffolds to have significant osteogenic properties and capability to improve cell growth and thus enhance bone regeneration. In this study, a poly(L-lactic acid) (PLLA) nanofiber scaffold-immobilized osteogenic growth peptide (OGP) was prepared via polydopamine (PDA) coating. X-ray photoelectron spectroscopy (XPS), contact angle measurement, and scanning electron microscopy (SEM) were used to determine the OGP immobilization, hydrophilicity and surface roughness of the samples. The SEM and fluorescence images demonstrate that the PLLA nanofiber scaffolds immobilized with the OGP have excellent cytocompatibility in terms of cell adhesion and proliferation. The ALP activity and the Runx2 and OPN expression results indicated that the PLLA nanofiber scaffolds immobilized with OGP significantly enhanced the osteogenic differentiation and calcium mineralization of hMSCs in vitro. A rat model of critical skull bone defect was selected to evaluate the bone formation capacity of the scaffolds. Micro CT analysis and histological results demonstrated that the PLLA scaffolds immobilized with OGP significantly promoted bone regeneration in critical-sized bone defects. This study verifies that the PLLA scaffold-immobilized OGP has significant potential in bone tissue engineering.

\section{Introduction}

Critical-sized bone defects caused by trauma, tumor or osteomyelitis have become challenging problems in the orthopaedic field. ${ }^{1}$ At present, autogenous bone and allogenic bone are being widely applied to repair the abovementioned bone defects. However, infection, disease transmission, immune rejection and limited sources have restricted the clinical translations of these materials to a large extent. ${ }^{2,3}$ In the past few decades, biomedical implants based on metals, polymers, ceramics and their composites or hybrids have been extensively studied and reported. ${ }^{\mathbf{4} \mathbf{1 4}}$ Based on the diverse physicochemical properties of different materials, various fabrication strategies have been developed involving 3D printing, eco-friendly supercritical fluid technology, electrospinning, etc. ${ }^{15-18}$ For instance,

\footnotetext{
${ }^{a}$ Department of Orthopaedic Surgery, The First Affiliated Hospital of Soochow University, Suzhou, Jiangsu, 215006, PR China.E-mail: sudachenliang1972@gmail. com; Tel: +86-512-65223637

${ }^{b}$ Department of Orthopaedic Surgery, The Affiliated Jiangyin Hospital of Medical College of Southeast University, Jiangyin, Jiangsu, 215600, PR China

${ }^{c}$ Suzhou TCM Hospital Affiliated to Nanjing University of Chinese Medicine, China ${ }^{d}$ Institute for Cardiovascular Science \& Department of Cardiovascular Surgery of the First Affiliated Hospital, Soochow University, Suzhou, Jiangsu, 215007, PR China ${ }^{e}$ Orthopedic Institute, Soochow University, Suzhou, Jiangsu, 215007, PR China
}

3D printing has been widely utilized to fabricate polymer-based scaffolds with desired porous architectures in a precise way. Among these materials, the poly(L-lactic acid) (PLLA) electrospun fiber has a series of desirable properties including large specific surface area, ability to mimic the extracellular matrix architecture, and controllable pore size, all of which are important for bone tissue regeneration materials; ${ }^{19-27}$ however, pure PLLA electrospun fibers are unsuitable for cell adhesion and proliferation because of their inappropriate surface properties; ${ }^{28-31}$ in addition, lack of active growth factors limits their capabilities of repairing defects. ${ }^{32}$ In these cases, various physical and chemical methods have thus been developed to improve the cell affinity of these synthetic substrates. ${ }^{33-36}$

In recent years, inspired by the biological protein secretion of mussels, surface modification based on a polymerized dopamine (polydopamine, PDA) coating layer has become a promising method to achieve bone tissue engineering biomaterials because of its simplicity, efficacy and low-cost; ${ }^{37-39}$ the PDA layer with catechol or diketone groups can stably incorporate biomacromolecules, such as proteins and peptides containing amino and thiol groups, via Schiff-base or Michael addition reactions. ${ }^{\mathbf{4 0 - 4 2}}$ For instance, the dopamine coating layer-immobilized vascular endothelial growth factor (VEGF) on a Ti-based bio-substitute can significantly promote the hMSCs 
to differentiate into endothelial cells. ${ }^{43}$ In addition, dopamine coating layer-immobilized HA was reported to increase cytocompatibility and osteogenic potential of the scaffold. ${ }^{44}$ Thus, the development of PLLA scaffolds coated with PDA is highly promising to bind osteogenic active factors for the repair of bone defects of critical size; however, to date, only few studies have been reported on this topic. ${ }^{\mathbf{4 5 , 4 6}}$

Among numerous osteogenic active factors, the osteogenic growth peptide (OGP) exists in the human body and has 14 amino acid sequences, which can promote hMSC proliferation and osteogenic differentiation. ${ }^{47,48}$ Traditional methods for loading OGP onto polymeric scaffolds include physical absorption. However, in this system, OGP can be easily diluted and may have a burst release from the material. ${ }^{49}$ Studies have reported that dopamine coated with catechol and amino groups immobilizes the osteogenic activity factor via Michael addition or chemical reaction, ${ }^{45}$ which have advantages of simple preparation, mild fabrication condition and immobilization of protein peptide, showing great capacities in bone tissue engineering.

In the present study, PLLA nanofibers were prepared by an electrospinning technique, and the surface of the PLLA nanofibers was modified by a PDA coating layer and then immobilized with the OGP. In vitro biocompatibility and prodifferentiation performance of the PLLA scaffolds immobilized with the OGP were evaluated by culturing these scaffolds with hMSCs. Moreover, the scaffolds were implanted in the critical-sized skull bone defect in a rat model to evaluate their osteogenic properties.

\section{Results}

\section{Physicochemical properties of the scaffolds}

The morphology of the PLLA, PLLA-PDA and PLLA-PDA-OGP scaffolds were visualized by SEM, as shown in Fig. 1a. The images show that all of the samples consist of interconnected pores and randomly distributed fibers. The average diameters of the fibers that build up these three types of scaffolds are similar; however, a slight increase in the average diameters is observed after loading PDA, and a further slight increase is observed after immobilizing the OGP (Fig. 1b). Interestingly, the surface of the PLLA scaffold fibers was smooth, whereas a few particles were observed on the surface of the PLLA-PDA scaffold fibers and distinct particles were found on the surface of the PLLA-PDA-OGP scaffold fibers (Fig. 1a). The surface water contact angle reflects the hydrophilicity of the fibrous scaffolds, which will influence protein absorption and subsequent cell adhesion on the membranes. ${ }^{\mathbf{5 0 , 5 1}}$ The effect of the immobilized PDA and OGP on the water contact angle of the fibrous scaffolds is shown in Fig. 1a and c. The PLLA scaffolds had the water contact angle of $122.5 \pm 7.3^{\circ}$ (Fig. 2a and c), indicating the inherent hydrophobicity of PLLA. After PDA coating, the water contact angle of the PLLA-PDA scaffolds dramatically decreased to $32.7 \pm 3.9^{\circ}$ (Fig. 1a and c); this was attributed to the presence of a hydrophilic amino group in the PDA molecules. Moreover, the water contact angle of the PLLA-PDA-OGP scaffolds was further decreased to $15.6 \pm 4.3^{\circ}$ (Fig. 1c); this indicated the complete hydrophilic surface of the scaffolds.

The surface chemical compositions of the scaffolds were determined by XPS. Fig. 3a illustrates the wide-scan XPS spectra obtained by scanning the samples, and the elemental peaks for the electrons $\mathrm{C}$ 1s and $\mathrm{O}$ 1s were observed for all the samples. However, new nitrogen ( $\mathrm{N}$ 1s) peaks were found in the spectra of both the PLLA-PDA scaffolds and PLLA-PDA-OGP scaffolds, whereas no nitrogen ( $\mathrm{N}$ 1s) peak was observed in the PLLA scaffolds (Fig. 2a); this confirmed that the PDA was successfully loaded onto the corresponding scaffolds. Furthermore, an intensifying $\mathrm{N}$ 1s peak was found in the spectrum of the PLLAPDA-OGP scaffolds when compared with the case of the PLLAPDA scaffolds. This was attributed to the higher abundance of nitrogen components in the OGP molecules than in the PDA molecules, and the results indicated that the OGP peptides were successfully immobilized on the PLLA-PDA scaffolds. Moreover, quantitative elemental distribution (C, O and $\mathrm{N}$ content) of three types of samples was further evaluated to support the immobilization of the OGP peptides on the PLLA-PDA scaffolds (Fig. 2b). The results indicated that the $\mathrm{N}$ content in the PLLAPDA-OGP scaffolds (8.7\%) was higher than that in the PLLA-PDA scaffolds $(3.9 \%)$, and no $\mathrm{N}$ component was found in the PLLA scaffolds $(0 \%)$. The results were also supported by previous studies reporting that the PDA coating increased the $\mathrm{N}$ peaks when compared with the case of the bare substrate, and peptide immobilization further increased the $\mathrm{N}$ peaks. ${ }^{52,53}$ The surface chemical structures of PLLA, PLLA-PDA and PLLA-PDA-OGP were analyzed by FTIR, and the result is shown in Fig. 2c. The bands at approximately $1750 \mathrm{~cm}^{-1}$ and $2957 \mathrm{~cm}^{-1}$ were attributed to the stretching vibration of carbonyl and $\mathrm{O}-\mathrm{H}$ asymmetric vibration of PLLA. Compared to the case of the pure PLLA scaffolds, some new absorption peaks at $1501 \mathrm{~cm}^{-1}$ and $1615 \mathrm{~cm}^{-1}$ appeared after modification of the pure scaffold with PDA. The absorption peak at $1615 \mathrm{~cm}^{-1}$ was ascribed to the overlapping of the $\mathrm{C}=\mathrm{C}$ stretching vibration in the aromatic ring and $\mathrm{N}-\mathrm{H}$ bending vibration, and the peaks at $1501 \mathrm{~cm}^{-1}$ were assigned to the $\mathrm{N}-\mathrm{H}$ shearing vibration of PDA. ${ }^{54}$

\section{Release behavior of the OGP}

The release behavior of the OGP was evaluated by utilizing both the PLLA-OGP and the PLLA-PDA-OGP scaffolds. Fig. 3 shows the percentage of OGP released from two types of scaffolds against time. For the PLLA-OGP scaffolds, OGP exhibited a burst release in the first 7 days, and the percentage of the OGP released from PLLA-OGP reached $82 \%$ at this time point. For the samples treated with PDA (PLLA-PDA-OGP), OGP showed a much slower release when compared with the case of the scaffolds without PDA treatment (PLLA-OGP). Specifically, the percentage of OGP released from PLLA-PDA-OGP reached 12\% and $26 \%$ at the timepoints of 7 days and 28 days, respectively.

\section{Cell adhesion and proliferation}

Cell adhesion and proliferation are the basic factors for the evaluation of the biocompatibility of scaffolds. In this study, hMSCs were seeded in these three types of scaffolds and 

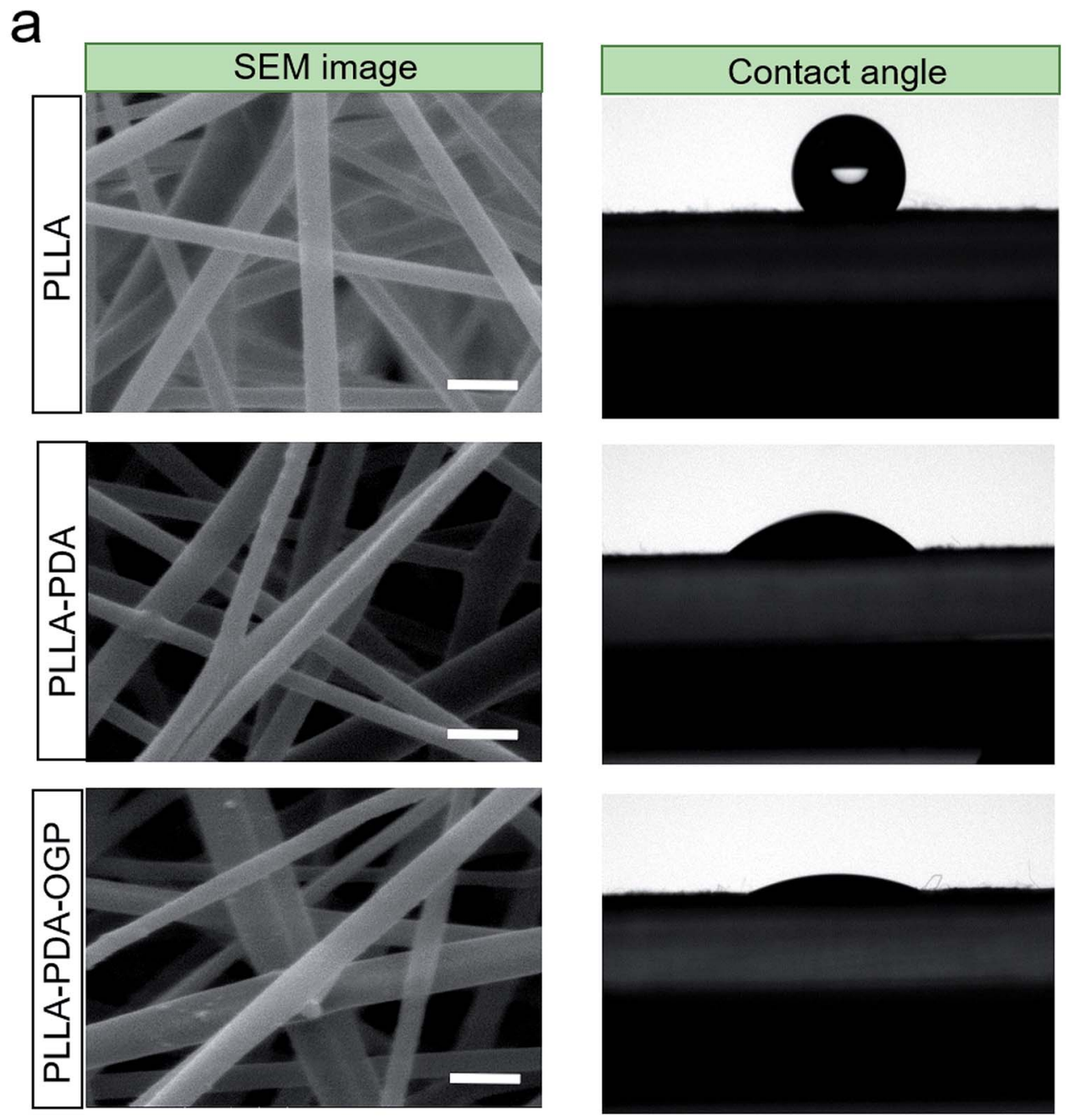

b

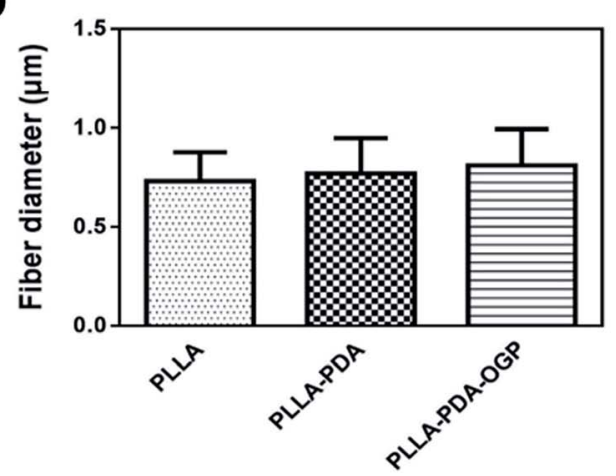

C

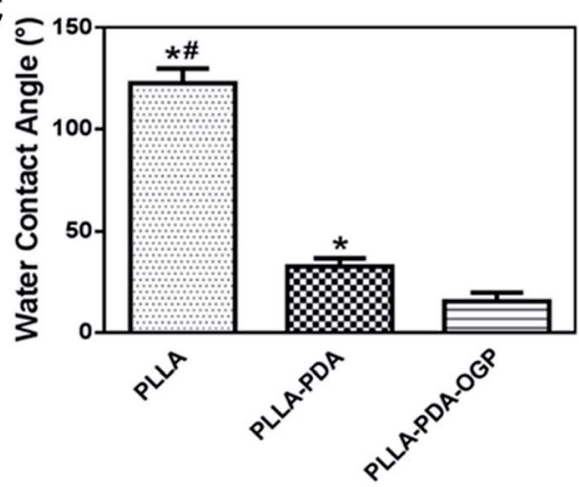

Fig. 1 Microstructure and hydrophilicity of the scaffolds. (a) SEM images and images of water contact angles of the scaffolds. The scale bar indicates $2 \mu \mathrm{m}$. (b) Fiber diameters of the scaffolds. (c) Water contact angles of the scaffolds. "*" indicates significant difference as compared to the PLLA-PDA-OGP group, "\#" indicates significant difference as compared to the PLLA-PDA group $(P<0.05)$.

cultured for 1,3 and 7 days, and the number of cells was measured by the CCK-8 assay. As shown in Fig. 4, the cells loaded on all the three types of scaffolds had significant proliferation from day 1 to day 7. Specifically, the number of cells in the PLLA-PDA scaffolds presented an obvious increase as compared to those in the PLLA scaffolds at every time point; this indicated that the PDA coating improved the cell adhesion and proliferation. Furthermore, the proliferation of cells on the PLLA-PDA-OGP scaffolds was further enhanced than that on the PLLA-PDA scaffolds.

To further observe cell adhesion on the three types of scaffolds, the morphology of the hMSCs cultured on various 
a
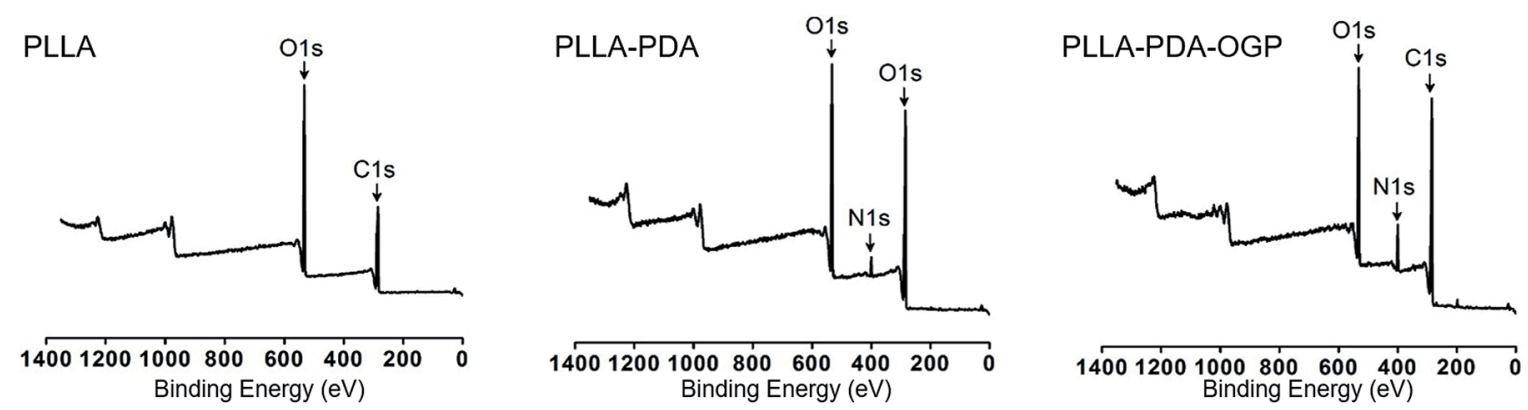

b
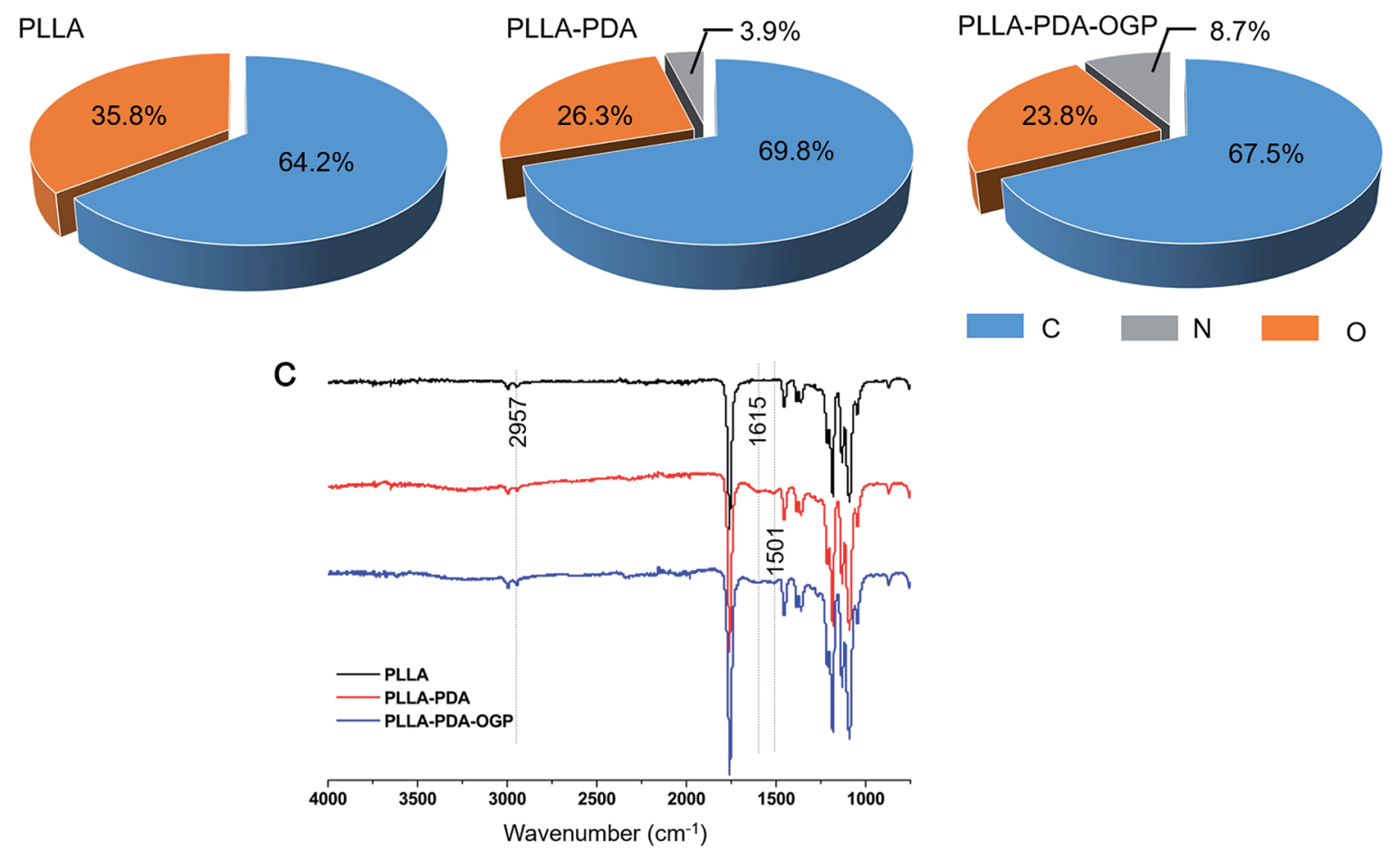

Fig. 2 X-ray photoelectron spectroscopy (XPS) of the sample. (a) XPS peaks of the PLLA, PLLA-PDA and PLLA-PDA-OGP scaffolds. (b) Atomic chemical composition of each sample surface. (c) FTIR analysis of different samples.

scaffolds was visualized using a fluorescence microscope and SEM. Fig. 5 exhibits the fluorescence images of the cells loaded onto different scaffolds. After 1 day of culture, the cells adhered on the scaffolds loaded with OGP showed larger spreading areas when compared with those adhered on PLLA and PLLA-PDA. At the timepoint of 3 days, the cells seeded on all the scaffolds show a well-spread morphology, suggesting that all these scaffolds have relatively good biocompatibility. However, the cells on both the PLLA-PDA scaffolds and the PLLA-PDA-OGP scaffolds presented a fusiform shape (Fig. 5), which was consistent with the previous report in which both the PDA coating and OGP improved the biocompatibility of polymeric scaffolds and thus facilitated cell adhesion and growth. ${ }^{55,56}$ At day 7, the cells on the PLLA-PDA-OGP scaffolds are highly fused as a multilayer structure (Fig. 5), and this result also implied that the immobilized OGP further improved the cell growth and proliferation. ${ }^{57}$ Fig. 6 shows the SEM images of the cells seeded on different scaffolds. The cells in all the scaffolds were spread very well, and the cells in both the PLLA-PDA scaffolds and the PLLAPDA-OGP scaffolds exhibited enhanced adhesion and proliferation; this was consistent with the results obtained via the fluorescence images.

\section{In vitro osteogenesis}

ALP is a well-known phosphatase enzyme that can be used as an early marker during the process of osteogenic differentiation. ${ }^{58}$ In this study, hMSCs loaded on different scaffolds were cultured for 14 days, and both alizarin red S assay and ALP activity assay were utilized to evaluate the osteogenic differentiation of hMSCs. Fig. 7a shows the three types of samples stained with alizarin red $\mathrm{S}$. The results demonstrated a slightly intense stain on both the PLLA scaffolds and the PLLA-PDA scaffolds, whereas an obviously intense stain was observed on the PLLAPDA-OGP scaffolds. The results were also supported by those 


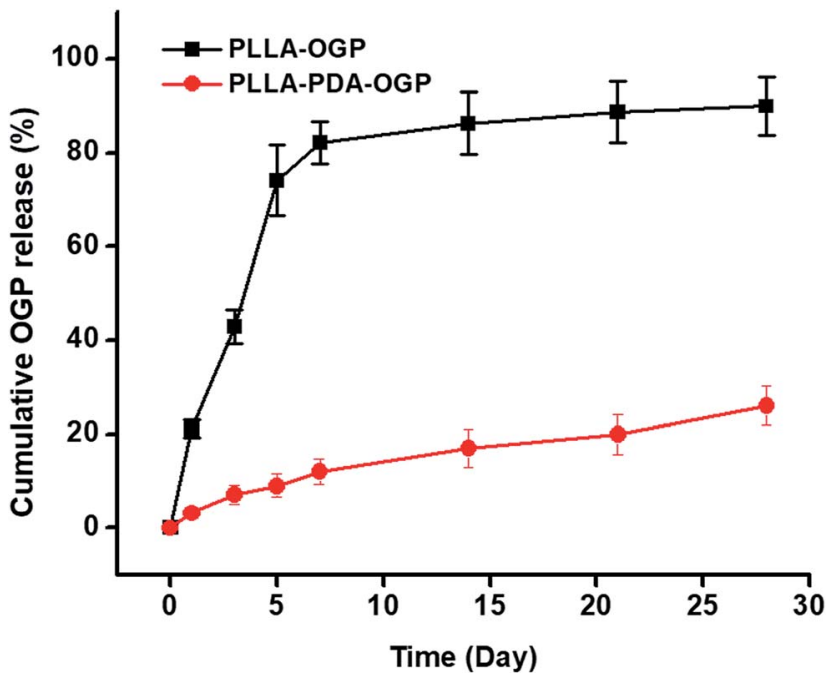

Fig. 3 Cumulative release of OGP from the PLLA-OGP scaffolds and PLLA-PDA-OGP scaffolds.

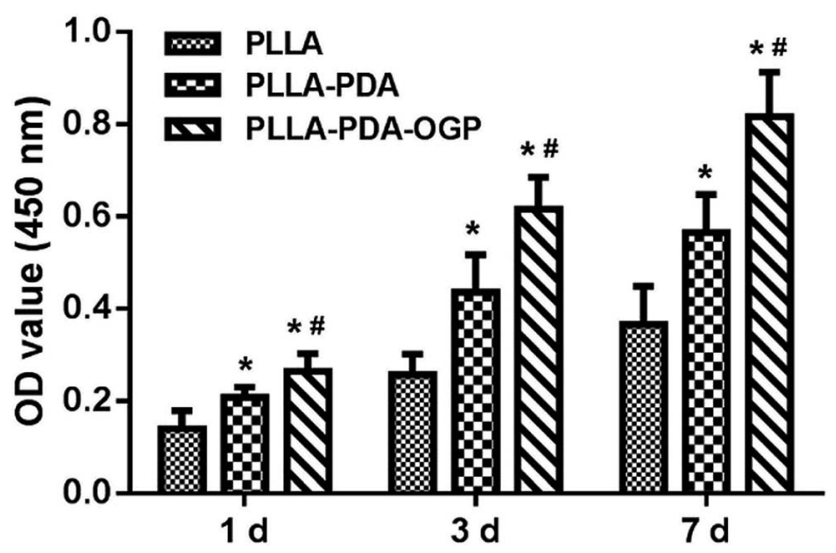

Fig. 4 Proliferation of hMSCs cultured on various scaffolds after 1, 3, and $7 \mathrm{~d}$. "*" indicates significant difference as compared to the PLLA group, "\#" indicates significant difference as compared to the PLLAPDA group $(P<0.05)$.

obtained via the quantitative mineralization studies. As shown in Fig. 7b, the PLLA scaffolds and the PLLA-PDA scaffolds showed no significant difference in the ALP activity $(P>0.05)$, whereas the PLLA-PDA-OGP scaffolds exhibited highest calcium content with significant difference when compared with both the PLLA scaffolds and the PLLA-PDA scaffolds; this indicated that OGP could significantly promote osteogenic differentiation of the hMSCs.

To further evaluate the osteogenic differentiation of these scaffolds, immunofluorescence stain (Fig. 8a) and qRT-PCR analysis (Fig. 8b) were utilized to investigate the osteogenesisrelated markers of Runx 2 and OPN. The immunofluorescence images indicated that the Runx2 (Red) and OPN (Green) protein expression were extremely limited on both the PLLA scaffolds and the PLLA-PDA scaffolds, whereas these proteins were significantly expressed on the PLLA-PDA-OGP scaffolds. Fig. 8b displays the quantitative Runx2 and OPN expression on three types of scaffolds. The results indicate that there is a slight increase in the Runx2 and OPN expression on the PLLA-PDA scaffolds as compared to those on the PLLA scaffolds; however, there is no statistical difference between the protein expressions observed on these two types of scaffolds. On the other hand, a significantly highest expression value of Runx2 and OPN was observed on the PLLA-PDA-OGP scaffolds when compared with the cases of other types scaffolds.

\section{In vivo bone regeneration}

The bone formation capacity of these three types of scaffolds was evaluated by implanting the scaffolds in bone defects with critical size. Fig. 9a shows the reconstruction images of the bone defects treated with different types of scaffolds. The images indicated that the bone formations in the defects treated with all the proposed scaffolds were significant than those in the defects without any implant materials, and the PLLA-PDA-OGP group had the most significant bone formation among all the groups. Fig. 9b exhibits the quantitative bone formation of different groups. The BV/TV values in both the PLLA group $(21.74 \pm 7.39 \%)$ and the PLLA-PDA group $(32.05 \pm 8.22 \%)$ were enhanced as compared to the case of the defect-only group (6.55 $\pm 3.2 \%$ ); this indicated that the PLLA-based scaffolds were positive to guide the bone regeneration. Moreover, new bone formation was significantly increased in the PLLA-PDA-OGP group $(68.99 \pm 13.78 \%)$, this was attributed to the osteogenic effects of OGP, and the results were also supported by the in vitro experiments.

Fig. 10 shows the H\&E and Masson staining of the tissues in bone defects. The histological results indicated that the bone defects in the defect-only group were filled with loose scar tissues, whereas the defects in the PLLA and PLLA-PDA groups were filled with degraded implants with newly formed bone and collagen tissues. However, the largest newly mature bone and collagen were observed in the PLLA-PDA-OGP group, and new blood vessels were also observed.

\section{Discussion}

Herein, to achieve tissue repairing scaffold materials, PLLA scaffolds were fabricated by the electrical spinning technique using the PLLA fibers with micro-scale diameter, exhibiting extremely high specific surface areas and porosity. Moreover, due to the electrical spinning process, these PLLA fibers were deposited randomly, forming a highly connective porous architecture. Generally, high porosity and interconnectivity of a structure architecture enhance the mass exchange of the scaffold and the loading and releasing efficiencies of biological cargos, thereby improving the capacity of the scaffold for tissue repair and regeneration. Besides structural design, the surface modification is of great importance for improving the tissue regeneration capacity of scaffolds. Due to the inherent hydrophobic property of these materials, the adhesion of protein and cells to the PLLA materials is poor. To increase the surface toughness and hydrophilicity of polymeric materials, incorporation of other hydrophilic materials (e.g., some inorganic 

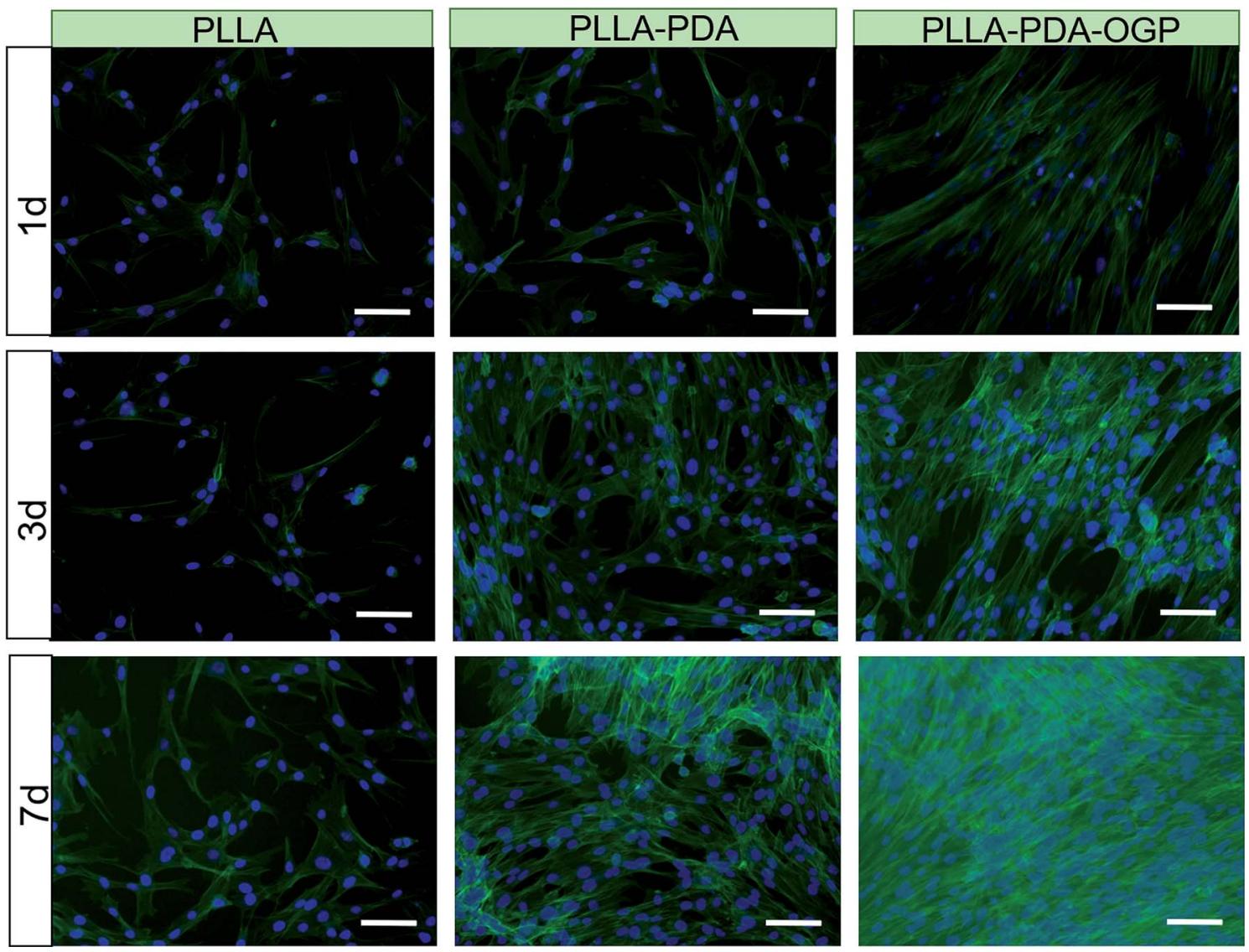

Fig. 5 Morphology of hMSCs cultured on the different scaffolds. Fluorescence images of F-actin (green) and nuclei (blue) in hMSCs cultured in scaffolds for 1,3 and 7 days. The scale bar indicates $100 \mu \mathrm{m}$.

nanoparticles) ${ }^{59}$ or creating a hydrophilic coating layer ${ }^{30,60}$ are effective ways and have been adapted in many studies. In this study, the PLLA fibers coated with PDA or OGP do not change much in terms of diameters and porous architecture but show a hydrophilic surface as compared to pure PLLA fibers, which is expected to increase the protein and cell adhesion. Moreover, the deposition of the PDA and OGP molecules makes the surface of the PLLA fibers rougher when compared with those without surface treatment. This was also supported by other studies in which PDA coating and peptide immobilization could improve the roughness of the substrate and induce cell adhesion and growth. ${ }^{61,62}$ Moreover, the release behavior of OGP from the scaffolds with and without the PDA coating suggested that the PDA coating formed interaction with the OGP molecules and helped maintain the OGP in the porous scaffolds. In this case, the scaffolds avoided the burst release of OGP and were capable of achieving their tissue repair function for a relatively long period.

Cell adhesion and proliferation were improved in the PDAcoated samples and further promoted in the OGP-modified scaffolds. Basically, these results were attributed to the following reasons: (1) the improved surface properties, such as hydrophilicity and surface roughness as abovementioned, of the PLLA fibers and (2) the sustained release of OGP from the PLLA-PDA-OGP scaffolds further promoted cell adhesion and proliferation. Similar results were obtained in other studies stating that the incorporation of OGP to bacterial cellulose enhanced the cell growth and proliferation..$^{63}$ Another study has also reported that OGP immobilized on the gradient substrate synthesized via click chemistry can enhance the MC3T3-E1 osteoblast proliferation. ${ }^{64}$ Moreover, ALP activity analysis and immunofluorescence staining suggested that OGP could significantly promote the osteogenic differentiation of the hMSCs. This was also supported by a previous study, which reported that the OGP-composited scaffold facilitated the osteogenic differentiation of osteoblasts. ${ }^{65}$ Other studies have also found that OGP immobilized on the PLGA/HA scaffolds can improve the mineralization and osteogenic differentiation of cells. ${ }^{55} \mathrm{M}$. et al. reported that PEU scaffolds containing OGP showed a higher and constant expression of Runx2 at 2 weeks when compared with other samples. ${ }^{66}$ Lai et al. found that OGPfunctionalized titanium implants showed highest expression of Runx2 and OPN as compared to other nonfunctional implants. ${ }^{67}$

A recent study has showed that polymeric materials crosslinked with OGP have an effect on facilitating the ingrowth of vessels. ${ }^{68}$ New bone formation and vascularization are critical for the application of the engineered scaffold in bone tissue engineering. ${ }^{69}$ In these cases, the PLLA-PDA-OGP scaffolds 

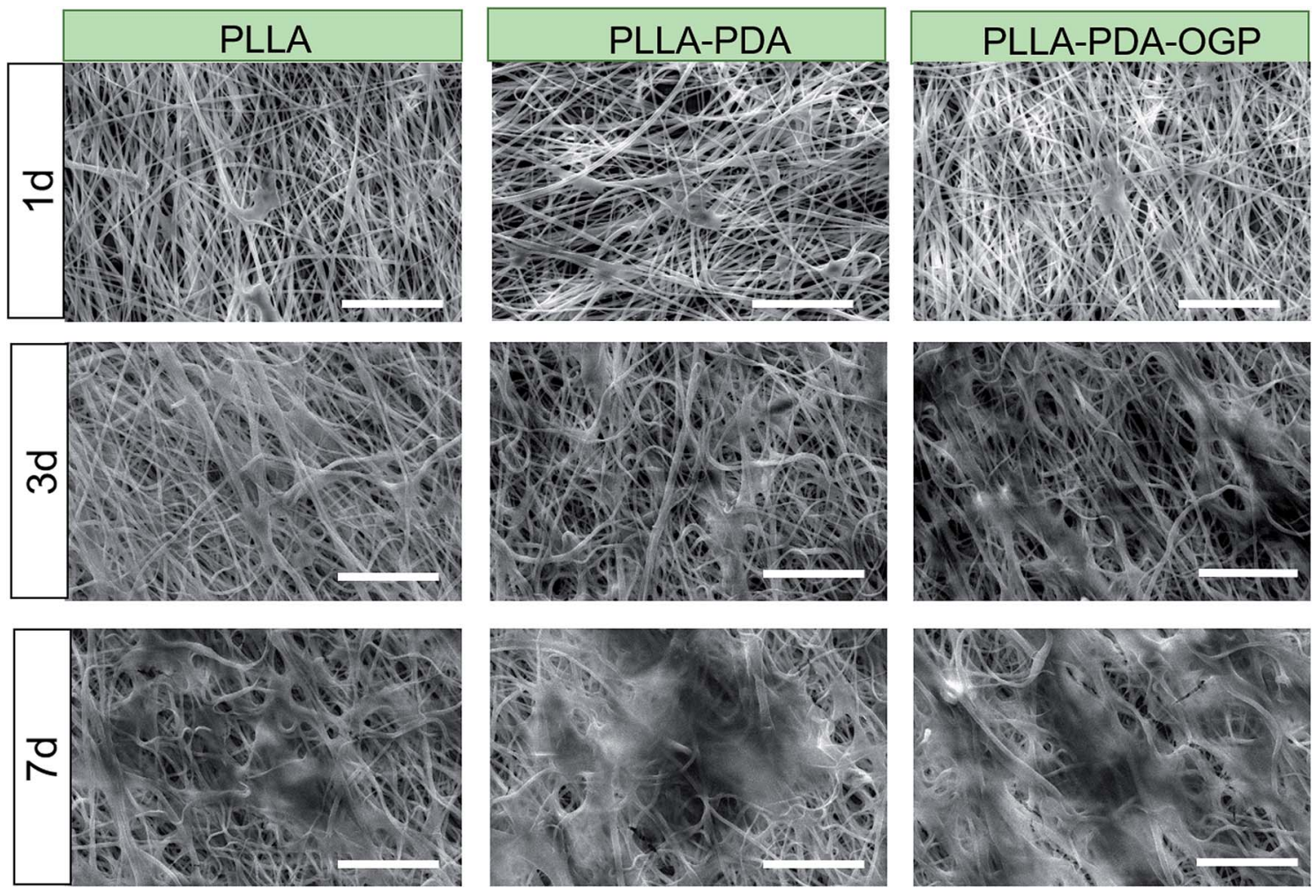

Fig. 6 Morphology of the hMSCs cultured on the different scaffolds. SEM images of hMSCs cultured in scaffolds for 1, 3 and 7 days. The scale bar indicates $100 \mu \mathrm{m}$

showed promising capacity of bone regeneration; this was also supported by our in vivo study results.

\section{Experimental}

Materials

Poly(L-lactic acid) (PLLA) was purchased from Daigang biotechnology (Jinan, China) (molecular weight 100000 Da). OGP (ALKRQGRTLYGFGG sequence) peptide was synthesized by Shanghai Jier biochemical (Shanghai, China). hMSCs were purchased from Saiye technology (Guangzhou, China). All other chemicals were purchased from GL Biochem (Shanghai, China).

\section{Preparation of the PLLA scaffolds and immobilization of the OGP}

The PLLA scaffolds were prepared by the electrospinning technique as previously described with slight modifications. ${ }^{41}$ Briefly, PLLA was dissolved in mixed (DCM/DMF $=2: 1 \mathrm{v} / \mathrm{v})$ solution to obtain a $3 \%(\mathrm{w} / \mathrm{v})$ polymer solution. As shown in Scheme 1, the solution was electrospun at an aluminum foilcovered collector rotation $\left(14 \mathrm{kV}, 23 \mathrm{G}\right.$ needle, $2 \mathrm{~mL} \mathrm{~h}^{-1}$ injection rate). For the OGP physical absorption, the PLLA scaffolds were immersed in the OGP solution $\left(2 \mathrm{mg} \mathrm{mL}^{-1}, 10 \mathrm{mM}\right.$ Tris$\mathrm{HCl}$ buffer, $\mathrm{pH}$ 8.5) and shaken on a rocker for $4 \mathrm{~h}$ at room temperature. The scaffolds were then washed three times with distilled water to remove the unattached OGP and named as the PLLA-OGP scaffolds. To perform the dopamine coating, the PLLA scaffolds were immersed in a polydopamine (PDA) solution $\left(2 \mathrm{mg} \mathrm{mL} \mathrm{mL}^{-1}, 10 \mathrm{nM}\right.$ Tris-HCl buffer, $\mathrm{pH}$ 8.5) and shaken on a rocker for $4 \mathrm{~h}$ at room temperature. The PDA-coated scaffolds were then rinsed three times with distilled water to remove the unattached PDA molecules and named PLLA-PDA scaffolds. For the OGP immobilization, the PLLA-PDA scaffolds were immersed in the OGP solution $\left(2 \mathrm{mg} \mathrm{mL}^{-1}, 10 \mathrm{mM}\right.$ Tris-HCl buffer, $\mathrm{pH}$ 8.5) and shaken on a rocker for $4 \mathrm{~h}$ at room temperature. The scaffolds were then washed three times with distilled water to remove the unattached OGP and termed as PLLA-PDA-OGP scaffolds.

\section{Characterization of the scaffolds}

The surface morphology of the scaffolds was examined using a scanning electron microscope (SEM) (S-4800, Hitachi, Kyoto, Japan). The atomic chemical composition of the scaffolds was analyzed using X-ray photoelectron spectroscopy (XPS) (PHI 5802, Physical Electronics, London, UK). The FTIR spectra were obtained by accumulating 32 scans in the range of 450$4000 \mathrm{~cm}^{-1}$. The water contact angle was measured using a contact angle analyzer (DSA 25S, KRÜSS, GmbH Germany).

\section{Release behavior of the OGP from the PLLA scaffolds}

The PLLA-OGP and PLLA-PDA-OGP scaffolds weighing $10 \mathrm{mg}$ were immersed in PBS and stirred (60 RPM) at $37^{\circ} \mathrm{C}$. At the time points of 1, 3, 5, 7, 14, 21 and 28 days, PBS with OGP was obtained, and fresh PBS was added. The cumulative percentage of the OGP released from the scaffolds was calculated and plotted 
a
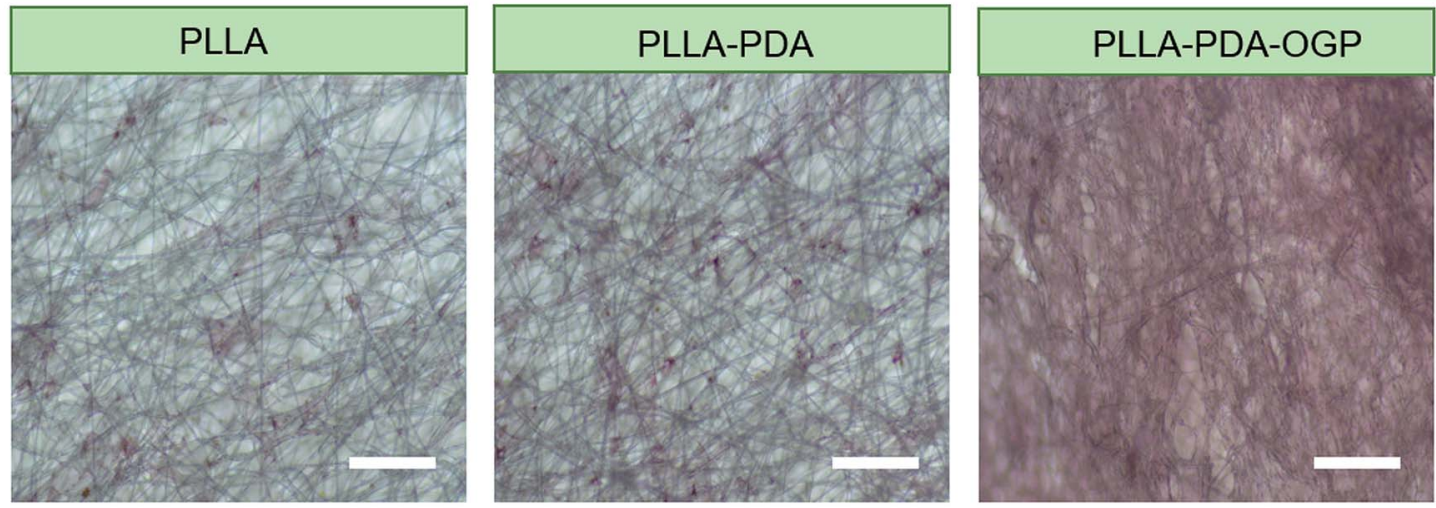

b

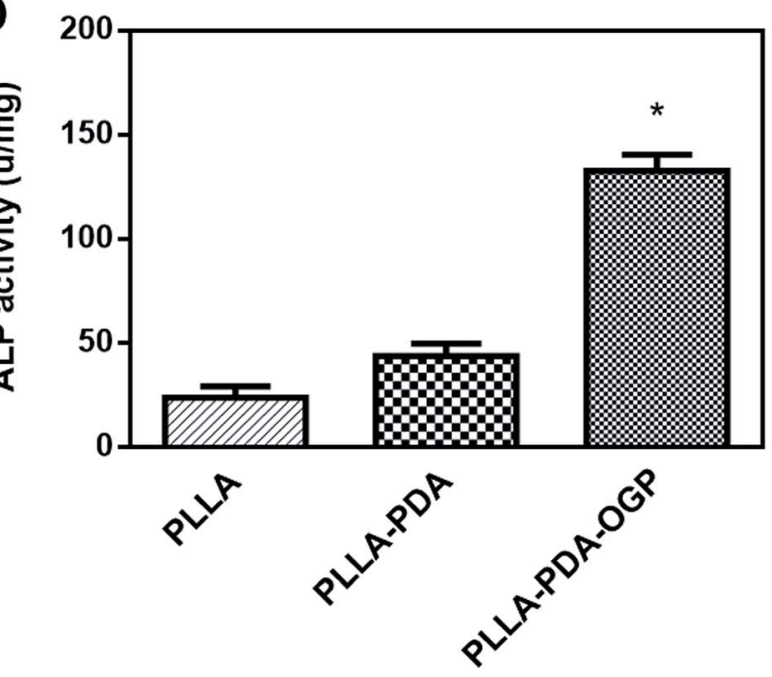

Fig. 7 Osteogenic differentiation of hMSCs cultured on different scaffolds. (a) Alizarin red S staining of hMSCs cultured on scaffolds for 14 days. The scale bar indicates $100 \mu \mathrm{m}$. (b) The ALP activity of hMSCs cultured on the scaffold for 14 days. "*" indicates significant difference as compared to the PLLA scaffold and the PLLA-PDA scaffold.

against time. The OGP release test was repeated 3 times utilizing different batches of samples.

\section{hMSC adhesion and proliferation analysis}

Scaffolds were cut into circular samples (diameter: $5 \mathrm{~mm}$ ) and placed in a 96-well plate. The samples were sterilized under UV light for $2 \mathrm{~h}$. The cells (hMSCs) suspended in a medium (lowglucose DMEM with 10\% FBS and 1\% PS) were seeded onto the scaffold at the density of $5.0 \times 10^{3}$ cells per well $(200 \mu \mathrm{L}$ per well). The cells were kept under standard conditions $\left(37^{\circ} \mathrm{C}, 5 \%\right.$ $\mathrm{CO}_{2}$, and $95 \%$ humidity), and the medium was replaced every 2 days. For SEM examination, the samples loaded with the cells were cultured for 1,3 and 7 days. At each time point, the samples were treated with paraformaldehyde (4\%) for $15 \mathrm{~min}$ and subsequently dehydrated using a series of gradient ethanol solutions $(10 \%, 20 \%, 30 \%, 50 \%, 70 \%, 80 \%$, 90\%, and 100\%). After this, the scaffolds were dried by a $\mathrm{CO}_{2}$ critical point drying method and sputter coated with gold for SEM observation.

For immunofluorescence staining, the scaffolds loaded with cells (after being cultured for 1, 3 and 7 days) were fixed in $4 \%$ paraformaldehyde at $4{ }^{\circ} \mathrm{C}$ for 15 minutes and then permeabilized with a $0.2 \%$ Triton $\mathrm{X}-100$ solution at $4{ }^{\circ} \mathrm{C}$ for $5 \mathrm{~min}$. After this reaction, the nuclei of the cells in the scaffolds were stained with FITC-phalloidin $(1: 200)$ and Hoechst 33342 (1:10000), respectively. Finally, the cells in the samples were visualized using a confocal microscope (LSM 5 Exciter, Carl Zeiss, Germany).

For cell proliferation analysis, the samples were subjected to 1,3 and 7 days of culture. At each desired timepoint, the medium of each well was replaced and added with a $20 \mu \mathrm{L}$ of CCK-8 (Dojindo, Kumamoto, Japan) solution followed by incubation at $37{ }^{\circ} \mathrm{C}$ for $3 \mathrm{~h}$. After this, $150 \mu \mathrm{L}$ solution of each well was taken in a new 96-well plate, and the absorbance of the solution was measured $(450 \mathrm{~nm})$ using a spectrophotometer.

\section{Alizarin red S staining}

After $14 \mathrm{~d}$ of culture, the samples were fixed with $4 \%$ paraformaldehyde for $30 \mathrm{~min}$ at room temperature and then washed twice with PBS. Subsequently, the samples were stained with Alizarin Red S (ARS) (Cyagen, Guangzhou, China) at $37{ }^{\circ} \mathrm{C}$ for 

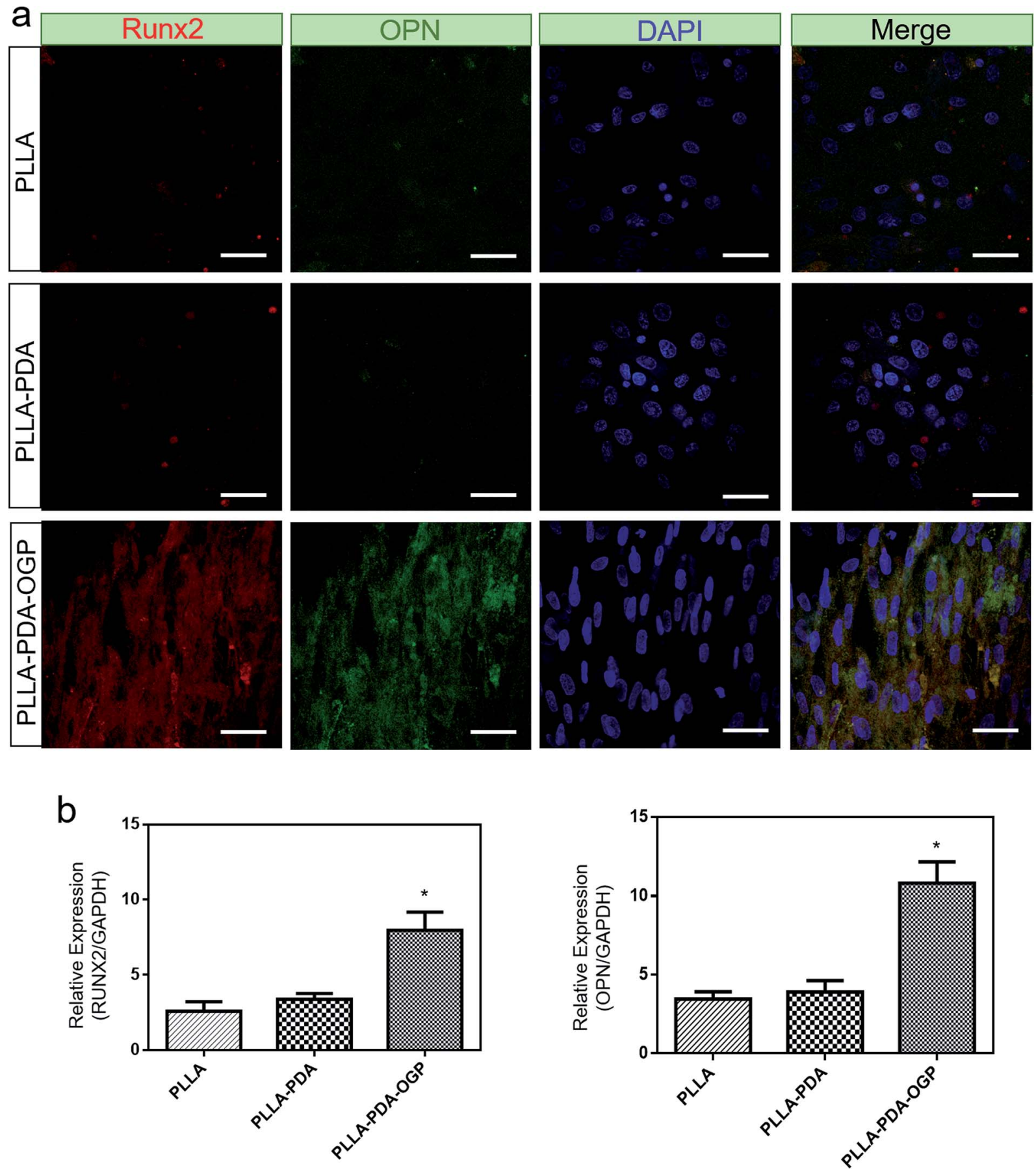

Fig. 8 In vitro differentiation of hMSCs cultured on different scaffolds. (a) Double immunofluorescence staining of Runx2 and OPN in hMSCs cultured on the scaffolds for 14 days. (b) qRT-PCR analysis to examine the expression of Runx2 and OPN in hMSCs cultured on the scaffolds for 14 days. "*" indicates significant difference as compared to the PLLA scaffold and the PLLA-PDA scaffold $(P<0.05)$.

15 min. After removing ARS, the samples were washed twice with PBS and observed and imaged using a microscope (bright field) (Olympus, Tokyo, Japan). For ALP activity, cells were washed 3 times with PBS and then lysed using lysis. The ALP activity was determined colorimetrically using the alkaline phosphatase assay kit (Biyuntian, P0321, China) and standardized on the total protein concentration calculated with the BCA protein assay reagent (Beyotime Biotech, P0010, China).

\section{Immunofluorescent staining and osteogenic gene expression}

For immunofluorescent staining, after $14 \mathrm{~d}$ of culture, the samples were fixed with $4 \%$ paraformaldehyde and permeabilized with $0.1 \%$ Triton $\mathrm{X}-100$ at $4{ }^{\circ} \mathrm{C}$ for $15 \mathrm{~min}$. Then, the samples were incubated with a blocking buffer (5\% FBS in PBS) at $37^{\circ} \mathrm{C}$ for $2 \mathrm{~h}$. The samples were subsequently incubated with a primary antibody (Runx 2 and OPN, $1: 100$, Abcam) for $1 \mathrm{~h}$ at room temperature. The samples were then incubated with 
a
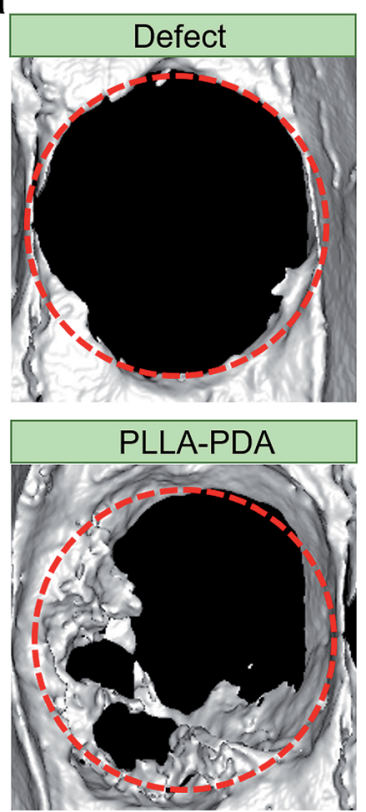
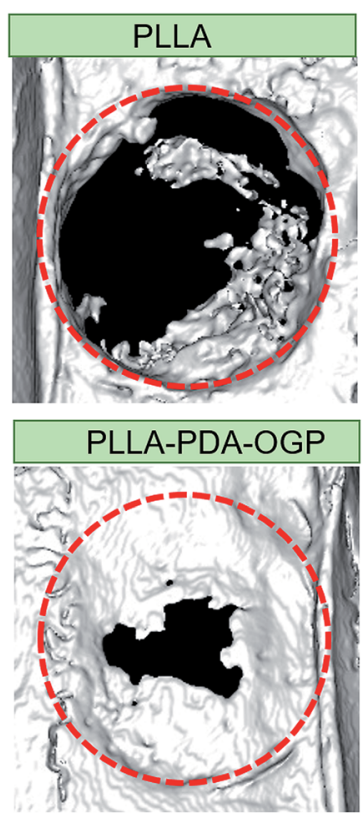

b

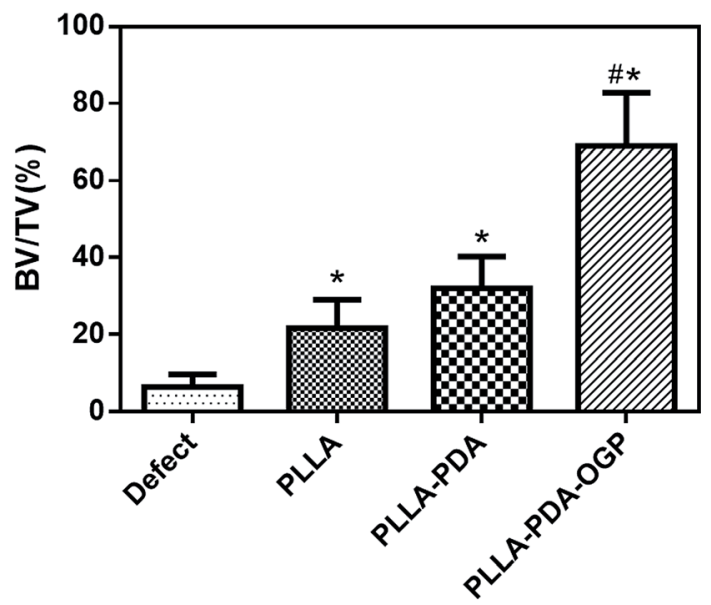

Fig. 9 Micro-CT analysis of the bone specimens retrieved eight weeks after the surgery. (a) Reconstructed Micro-CT images of the bone specimens implanted with scaffolds. (b) BV/TV (bone volume/tissue volume) of different groups after eight weeks. "*" indicates significant difference as compared to the defect-only group, "\#" indicates significant difference as compared to the PLLA-PDA group $(P<0.05)$.

a fluorescent dye-conjugated secondary antibody (Abcam, $1: 100$ ) for $1 \mathrm{~h}$ at room temperature. Nuclei were stained with Hoechst 33342. The samples were visualized using a confocal laser scanning microscope (Olympus LX71, Olympus).

For osteogenic gene expression, after $14 \mathrm{~d}$ of culture, the expression of the osteogenic genes, including Runt-related factor-2 (Runx2) and Osteopontin (OPN), was analyzed by the quantitative reverse transcription polymerase chain reaction (qRT-PCR). The extraction of RNA and procedure of qRT-PCR were performed as previously reported in the literature. $^{70}$ The expression level of each target gene was normalized by glyceraldehyde-3-phosphate dehydrogenase (GAPDH) using the comparative $C_{\mathrm{t}}$ method. The primers used for Runx2 were TCTTCCCAAAGCCAGAGCG (forward) and TGCCATTCGAGGTGGTCG (reverse). The primers used for OPN were GAGGAGAAGGCGCATTACAG (forward) and AAACGTCTGCTTGTCTGCTG (reverse).

\section{Rat skull critical size defect model and scaffold implantation}

Sprague-Dawley (SD) male rats were purchased from the Experiment Animal Center of Soochow University. The animal study was performed in strict accordance with the Guidance on the Treatment of Experimental Animals published by Ministry of Science and Technology of China (2006) and approved by the Committee of Experimental Animal a
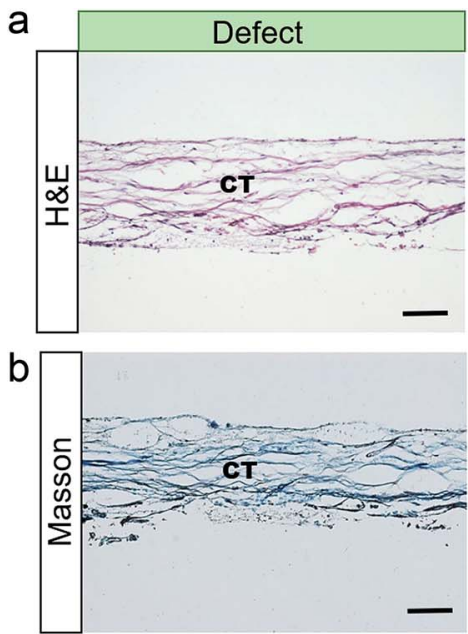
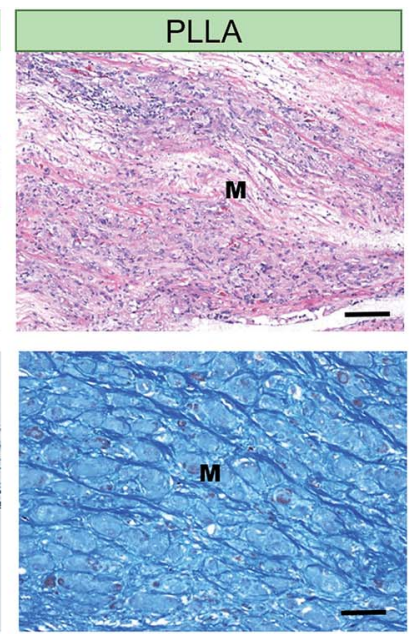
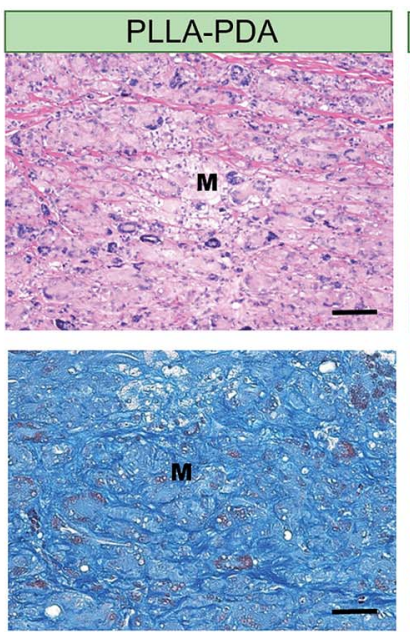
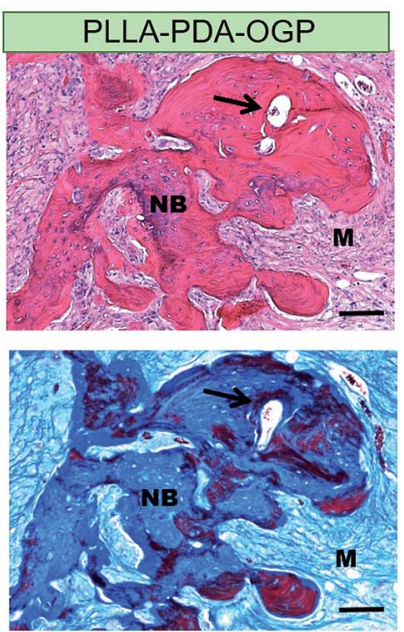

Fig. 10 H\&E (a) and Masson (b) staining of the samples after eight weeks of scaffold implantation. The scale bar indicates $100 \mu \mathrm{m}$ (CT = connective tissue, $M=$ material, $\mathrm{NB}=$ new bone). Black arrowhead indicates newly formed blood vessels in the regenerated bone. 

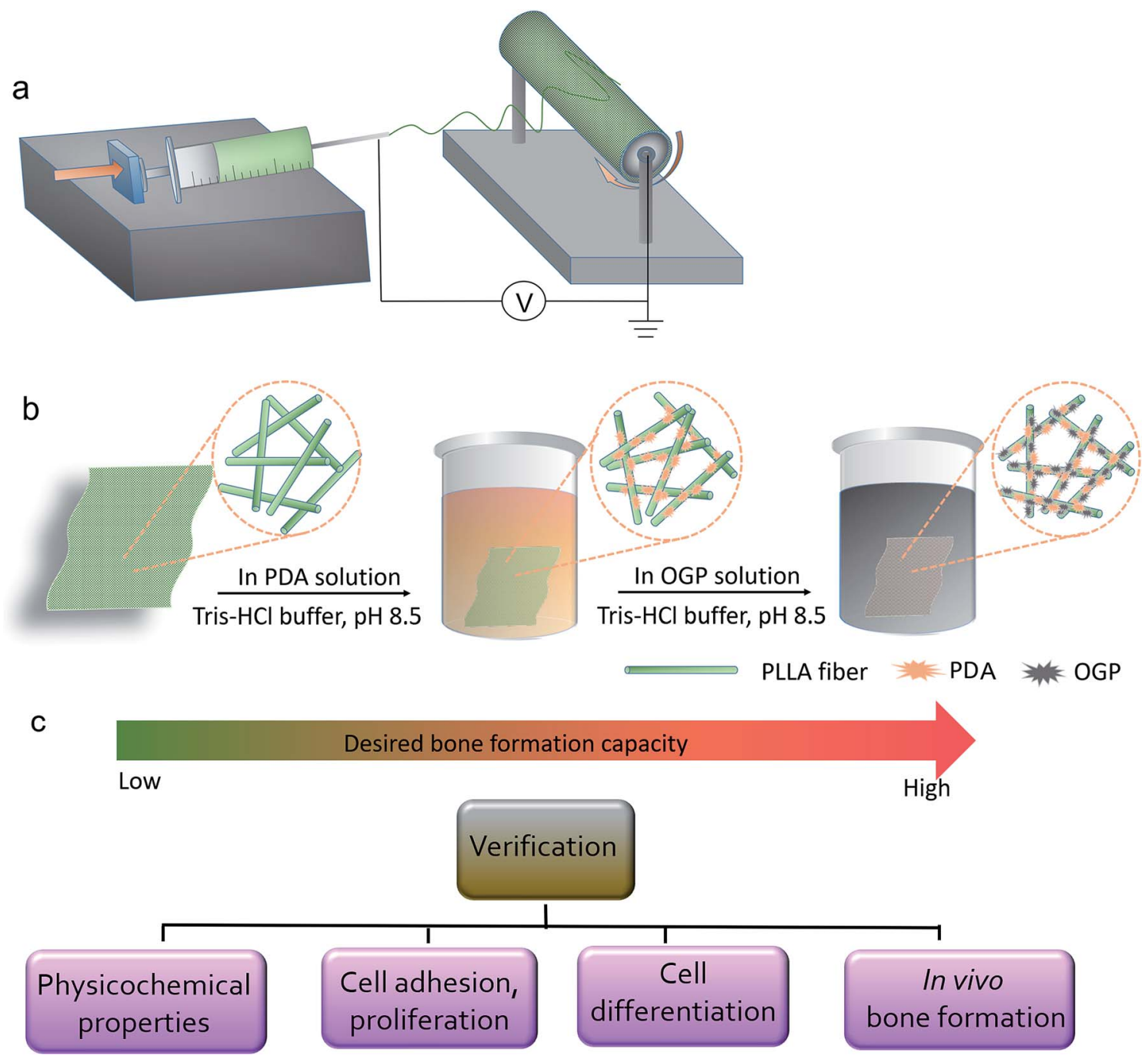

Scheme 1 Fabrication protocol of PLLA-based scaffolds: (a) schematic of the electrospinning device in this study. (b) Experimental steps of coating PDA and OGP molecules on the PLLA scaffolds. (c) Characterization aspects of the samples.

Administration of First Affiliated Hospital of Soochow University. Animals were kept in a regulated environment. All rats were anesthetized by nose cone $\left(1.5 \%\right.$ isoflurane in $\mathrm{O}_{2}$ at 1.5 $\mathrm{L} \mathrm{min}^{-1}$ ) during the surgery. Circle defects with a diameter of $4 \mathrm{~mm}$ were created on both sides of skull using a dental drill. The defects were either left empty or filled with the scaffolds. The SD rats were randomly divided into four groups $(n=6)$ named defect only, PLLA scaffold, PLLA-PDA scaffold, and PLLA-PDA-OGP scaffold. The surgical fields were sutured and sterilized with povidone iodine. After eight weeks, the animals were euthanized by $\mathrm{CO}_{2}$ inhalation followed by cervical dislocation, and the samples were harvested for microCT and histological analysis.

\section{Micro-computed tomography analysis}

The harvested samples were fixed in $10 \%$ paraformaldehyde for micro-CT scanning ( $65 \mathrm{kV}, 385 \mu \mathrm{A}$, and $1 \mathrm{~mm}$ AI filter; SkyScan 1176, SkyScan, Aartselaar, Belgium). A cylindrical volume of interest (VOI) with a diameter of $4 \mathrm{~mm}$ was used to measure the regenerated bone areas, and the images of the newly formed bone were reconstructed and analyzed using a system software (SkyScan CTVOX 2.1).

\section{Histological evaluation}

The harvested samples were fixed in $4 \%$ paraformaldehyde for 2 $\mathrm{d}$ and decalcified in formalin for over 1 week at room temperature. The samples were then dehydrated with graded ethanol (70-100\%) and embedded in paraffin. The samples were sliced into $5 \mu \mathrm{m}$ sections and stained with hematoxylin and eosin (H\&E) and Masson's trichrome stains, respectively. The stained specimens were subsequently observed using a bright field microscope (Zeiss Axiovert 200, Carl Zeiss Inc, Thornwood, NY, USA).

\section{Statistical analysis}

All quantitative data are expressed as mean \pm standard deviation. The data were analyzed using the $t$ test or ANOVA with 
Tukey's multiple comparison test. The $P$-values less than 0.05 were considered statistically significant.

\section{Conclusions}

In this study, OGP was successfully immobilized on the PLLA scaffolds via a PDA adhesion coating approach. The surface roughness, hydrophilicity and biocompatibility of the PLLA scaffolds were significantly enhanced by loading these scaffolds with PDA and OGP. The ALP activity and the Runx2 and OPN expression results indicate that the immobilization of OGP can significantly improve the in vitro osteogenic differentiation of hMSCs. A rat model of critical skull bone defect was utilized to evaluate the in vivo bone formation capacity of the PDA- and OGP-modified PLLA scaffolds. The micro-CT and histological analysis results demonstrated that the PLLA-PDA-OGP scaffolds showed promising capacity in the regeneration of critical bone defects.

\section{Conflicts of interest}

There are no conflicts to declare.

\section{Acknowledgements}

This work was supported by the National Natural Science Foundation of China (81371930, 21604059 and 81772312), Key Talented Man Project of Jiangsu Province (RC2011102) and Standardized Diagnosis and Treatment Project of Key Diseases in Jiangsu Province (BE2015641).

\section{Notes and references}

1 R. Dimitriou, E. Jones, D. McGonagle and P. V. Giannoudis, Bone regeneration: current concepts and future directions, BMC Med., 2011, 9, 66, DOI: 10.1186/1741-7015-9-66.

2 A. R. Amini, C. T. Laurencin and S. P. Nukavarapu, Bone tissue engineering: recent advances and challenges, Crit. Rev. Bioeng., 2012, 40(5), 363.

3 C. Delloye, O. Cornu, V. Druez and O. Barbier, Bone allografts: what they can offer and what they cannot, $J$. Bone Jt. Surg., Br. Vol., 2007, 89(5), 574-579.

4 C. Xu, H. Liu, H. Yang and L. Yang, A Green Biocompatible Fabrication of Highly Porous Functional Ceramics with High Strength and Controllable Pore Structures, J. Mater. Sci. Technol., 2016, 32(8), 729-732.

5 C. Xu, Z. Wei, H. Gao, Y. Bai, H. Liu, H. Yang, Y. Lai and L. Yang, Bioinspired Mechano-Sensitive Macroporous Ceramic Sponge for Logical Drug and Cell Delivery, $A d v$. Sci., 2017, 4(6), 1600410.

6 C. Xu, Y. Bai, S. Yang, H. Yang, D. A. Stout, P. A. Tran and L. Yang, A versatile three-dimensional foam fabrication strategy for soft and hard tissue engineering, Biomed. Mater., 2018, 13(2), 025018.

7 C. Xu, Y. Bai, H. Yang and L. Yang, Mechanically Modulated, Ultra-high Precision Logic Delivery of Molecules by Bio- inspired Macroporous Ceramic Sponge, MRS Adv., 2017, 2(19-20), 1125-1130.

8 W. Tang, D. Lin, Y. Yu, H. Niu, H. Guo, Y. Yuan and C. Liu, Bioinspired trimodal macro/micro/nano-porous scaffolds loading rhBMP-2 for complete regeneration of critical size bone defect, Acta Biomater., 2016, 32, 309-323.

9 S. Yang, K. F. Leong, Z. Du and C. K. Chua, The design of scaffolds for use in tissue engineering. Part I. Traditional factors, Tissue Eng., Part A, 2001, 8(1), 679-689.

10 W. Jiang, A. F. Cipriano, Q. Tian, C. Zhang, M. Lopez, A. Sallee, A. Lin, M. Alcaraz, Y. Wu and Y. Zheng, In Vitro Evaluation of $\mathrm{MgSr}$ and $\mathrm{MgCaSr}$ Alloys via Direct Culture with Bone Marrow Derived Mesenchymal Stem Cells, Acta Biomater., 2018, 72, 407-423.

11 C. Zhang, N. Driver, Q. Tian, W. Jiang and H. Liu, Electrochemical Deposition of Conductive Polymers onto Magnesium Microwires for Neural Electrode Applications, J. Biomed. Mater. Res., Part A, 2018, 106(7), 1887-1895.

12 N. Ignjatović, V. Savić, S. Najman, M. Plavšić and D. Uskoković, A study of HAp/PLLA composite as a substitute for bone powder, using FT-IR spectroscopy, Biomaterials, 2001, 22(6), 571-575.

13 M. Zhang, T. T. Yi, Y. M. Zhang, L. Zhang, W. Wu, A. L. Zhang and Z. J. Pan, Ornithoctonus huwenna spider silk protein attenuating diameter and enhancing strength of the electrospun PLLA fiber, Polym. Adv. Technol., 2011, 22(1), 151-157.

14 L. He, S. Liao, D. Quan, K. Ma, C. Chan, S. Ramakrishna and J. Lu, Synergistic effects of electrospun PLLA fiber dimension and pattern on neonatal mouse cerebellum C17.2 stem cells, Acta Biomater., 2010, 6(8), 2960-2969.

15 R. K. Kankala, K. Zhu, X. Sun, C. G. Liu, S. Wang and A. Chen, Cardiac Tissue Engineering on the Nanoscale, ACS Biomater. Sci. Eng., 2018, 4(3), 800-818.

16 R. K. Kankala, K. Zhu, J. Li, C. S. Wang, S. B. Wang and A. Z. Chen, Fabrication of arbitrary $3 \mathrm{D}$ components in cardiac surgery: from macro-, micro- to nanoscale, Biofabrication, 2017, 9(3), 032002.

17 R. K. Kankala, Y. S. Zhang, S. B. Wang, C. H. Lee and A. Z. Chen, Supercritical Fluid Technology: An Emphasis on Drug Delivery and Related Biomedical Applications, Adv. Healthcare Mater., 2017, 6(16), 1700433.

18 B. Q. Chen, R. K. Kankala, A. Z. Chen, D. Z. Yang, X. X. Cheng, N. Jiang, K. Zhu and S. B. Wang, Investigation of silk fibroin nanoparticle-decorated poly(l-lactic acid) composite scaffolds for osteoblast growth and differentiation, Int. J. Nanomed., 2017, 12, 1877-1890.

19 H. Qi, Z. Ye, H. Ren, N. Chen, Q. Zeng, X. Wu and T. Lu, Bioactivity assessment of PLLA/PCL/HAP electrospun nanofibrous scaffolds for bone tissue engineering, Life Sciences, 2016, 148, 139-144.

20 N. Barroca, A. Marote, S. I. Vieira, A. Almeida, M. H. Fernandes, P. M. Vilarinho and O. A. d. C. e. Silva, Electrically polarized PLLA nanofibers as neural tissue engineering scaffolds with improved neuritogenesis, Colloids Surf., B, 2018, 167, 93-103. 
21 X. Wang, T. Lou, W. Zhao, G. Song, C. Li and G. Cui, The effect of fiber size and pore size on cell proliferation and infiltration in PLLA scaffolds on bone tissue engineering, $J$. Biomater. Appl., 2016, 30(10), 1545-1551.

22 S. S. Liao, F. Z. Cui, W. Zhang and Q. L. Feng, Hierarchically biomimetic bone scaffold materials: nano-HA/collagen/PLA composite, J. Biomed. Mater. Res., Part B, 2004, 69(2), 158165, DOI: 10.1002/jbm.b.20035.

23 Y. Liu, H. Cui, X. Zhuang, Y. Wei and X. Chen, Electrospinning of aniline pentamer-graft-gelatin/PLLA nanofibers for bone tissue engineering, Acta Biomater., 2014, 10(12), 5074-5080, DOI: 10.1016/j.actbio.2014.08.036.

24 A. Majola, S. Vainionpää, K. Vihtonen, M. Mero, J. Vasenius, P. Törmälä and P. Rokkanen, Absorption, biocompatibility, and fixation properties of polylactic acid in bone tissue: an experimental study in rats, Clin. Orthop. Relat. Res., 1991, 268(268), 260.

25 H. R. B. Raghavendran, S. Puvaneswary, S. Talebian, M. R. Murali, S. V. Naveen, G. Krishnamurithy, R. Mckean and T. Kamarul, A Comparative Study on In Vitro Osteogenic Priming Potential of Electron Spun Scaffold PLLA/HA/Col, PLLA/HA, and PLLA/Col for Tissue Engineering Application, PLoS One, 2014, 9(8), e104389.

26 M. Sittinger, D. Reitzel, M. Dauner, H. Hierlemann, C. Hammer, E. Kastenbauer, H. Planck, G. R. Burmester and J. Bujia, Resorbable polyesters in cartilage engineering: affinity and biocompatibility of polymer fiber structures to chondrocytes, J. Biomed. Mater. Res., 1996, 33(2), 57-63.

27 X. T. Wen, H. S. Fan, Y. F. Tan, H. D. Cao, H. Li, B. Cai and X. D. Zhang, Preparation of Electrospun PLA Nanofiber Scaffold and the Evaluation In Vitro, Key Eng. Mater., 2005, 288-289, 139-142, DOI: 10.4028/www.scientific.net/ KEM.288-289.139.

28 M. R. Sprott, G. Gallego-Ferrer, M. J. Dalby, M. Salmerón-Sánchez and M. Cantini, Functionalization of PLLA with Polymer Brushes to Trigger the Assembly of Fibronectin into Nanonetworks, Adv. Healthcare Mater., 2019, 1801469.

29 Z. Khatri, A. W. Jatoi, F. Ahmed and I.-S. Kim, Cell adhesion behavior of poly ( $\varepsilon$-caprolactone)/poly (L-lactic acid) nanofibers scaffold, Mater. Lett., 2016, 171, 178-181.

30 K. Zhang, H. Zheng, S. Liang and C. Gao, Aligned PLLA nanofibrous scaffolds coated with graphene oxide for promoting neural cell growth, Acta Biomater., 2016, 37, 131-142.

31 L. T. Nguyen, S. Liao, C. K. Chan and S. Ramakrishna, Enhanced osteogenic differentiation with 3D electrospun nanofibrous scaffolds, Nanomedicine, 2012, 7(10), 15611575.

32 Y. Yang, M.-C. Porté, P. Marmey, A. J. El Haj, J. Amédée and C. Baquey, Covalent bonding of collagen on poly(L-lactic acid) by gamma irradiation, Nucl. Instrum. Methods Phys. Res., Sect. B, 2003, 207(2), 165-174, DOI: 10.1016/s0168583x(03)00456-7.

33 T. Jacobs, H. Declercq, N. De Geyter, R. Cornelissen, P. Dubruel, C. Leys, A. Beaurain, E. Payen and R. Morent,
Plasma surface modification of polylactic acid to promote interaction with fibroblasts, J. Mater. Sci.: Mater. Med., 2013, 24(2), 469-478, DOI: 10.1007/s10856-012-4807-z.

34 H. Park, J. W. Lee, K. E. Park, W. H. Park and K. Y. Lee, Stress response of fibroblasts adherent to the surface of plasmatreated poly(lactic-co-glycolic acid) nanofiber matrices, Colloids Surf., B, 2010, 77(1), 90-95, DOI: 10.1016/ j.colsurfb.2010.01.011.

35 N. G. Rim, S. J. Kim, Y. M. Shin, I. Jun, D. W. Lim, J. H. Park and $\mathrm{H}$. Shin, Mussel-inspired surface modification of poly $(\mathrm{L}-$ lactide) electrospun fibers for modulation of osteogenic differentiation of human mesenchymal stem cells, Colloids Surf., B, 2012, 91, 189-197, DOI: 10.1016/ j.colsurfb.2011.10.057.

36 Y. M. Shin, H. Shin and Y. M. Lim, Surface modification of electrospun poly(L-lactide-co- $\varepsilon$-caprolactone) fibrous meshes with a RGD peptide for the control of adhesion, proliferation and differentiation of the preosteoblastic cells, Macromol. Res., 2010, 18(5), 472-481, DOI: 10.1007/ s13233-010-0507-z.

37 S. Huang, N. Liang, Y. Hu, X. Zhou and N. Abidi, Polydopamine-Assisted Surface Modification for Bone Biosubstitutes, BioMed Res. Int., 2016, 2016, 2389895, DOI: 10.1155/2016/2389895.

38 H.-j. Cho, S. K. Madhurakkat Perikamana, J.-h. Lee, J. Lee, K.-M. Lee, C. S. Shin and H. Shin, Effective immobilization of BMP-2 mediated by polydopamine coating on biodegradable nanofibers for enhanced in vivo bone formation, ACS Appl. Mater. Interfaces, 2014, 6(14), 1122511235.

39 S. K. Madhurakkat Perikamana, J. Lee, T. Ahmad, Y. Jeong, D.-G. Kim, K. Kim and H. Shin, Effects of immobilized BMP-2 and nanofiber morphology on in vitro osteogenic differentiation of hMSCs and in vivo collagen assembly of regenerated bone, ACS Appl. Mater. Interfaces, 2015, 7(16), 8798-8808.

40 L. A. Burzio and J. H. Waite, Cross-linking in adhesive quinoproteins: studies with model decapeptides, Biochemistry, 2000, 39(36), 11147.

41 H. Lee, S. M. Dellatore, W. M. Miller and P. B. Messersmith, Mussel-inspired surface chemistry for multifunctional coatings, Science, 2007, 318(5849), 426-430, DOI: 10.1126/ science.1147241.

42 M. Sugumaran, H. Dali and V. Semensi, Chemical- and cuticular phenoloxidase- mediated synthesis of cysteinylcatechol adducts, Arch. Insect Biochem. Physiol., 1989, 11(2), 127-137.

43 C. K. Poh, Z. Shi, T. Y. Lim, K. G. Neoh and W. Wang, The effect of VEGF functionalization of titanium on endothelial cells in vitro, Biomaterials, 2010, 31(7), 1578-1585, DOI: 10.1016/j.biomaterials.2009.11.042.

44 X. Gao, J. Song, P. Ji, X. Zhang, X. Li, X. Xu, M. Wang, S. Zhang, Y. Deng, F. Deng and S. Wei, PolydopamineTemplated Hydroxyapatite Reinforced Polycaprolactone Composite Nanofibers with Enhanced Cytocompatibility and Osteogenesis for Bone Tissue Engineering, ACS Appl. 
Mater. Interfaces, 2016, 8(5), 3499-3515, DOI: 10.1021/ acsami.5b12413.

45 S. J. Lee, D. Lee, T. R. Yoon, H. K. Kim, H. H. Jo, J. S. Park, J. H. Lee, W. D. Kim, I. K. Kwon and S. A. Park, Surface modification of 3D-printed porous scaffolds via musselinspired polydopamine and effective immobilization of rhBMP-2 to promote osteogenic differentiation for bone tissue engineering, Acta Biomater., 2016, 40, 182-191, DOI: 10.1016/j.actbio.2016.02.006.

46 X. Zhao, Y. Han, J. Li, B. Cai, H. Gao, W. Feng, S. Li, J. Liu and D. Li, BMP-2 immobilized PLGA/hydroxyapatite fibrous scaffold via polydopamine stimulates osteoblast growth, Mater. Sci. Eng., C, 2017, 78, 658.

47 I. Bab, D. Gazit, M. Chorev, A. Muhlrad, A. Shteyer, Z. Greenberg, M. Namdar and A. Kahn, Histone H4-related osteogenic growth peptide (OGP): a novel circulating stimulator of osteoblastic activity, EMBOJ., 1992, 11(5), 1867.

48 N. Gabarin, H. Gavish, A. Muhlrad, Y. C. Chen, M. NamdarAttar, R. A. Nissenson, M. Chorev and I. Bab, Mitogenic G(i) protein-MAP kinase signaling cascade in MC3T3-E1 osteogenic cells: activation by C-terminal pentapeptide of osteogenic growth peptide [OGP(10-14)] and attenuation of activation by cAMP, J. Cell. Biochem., 2001, 81(4), 594.

49 S. C. Pigossi, G. J. de Oliveira, L. S. Finoti, R. Nepomuceno, L. C. Spolidorio, C. Rossa Jr, S. J. Ribeiro, S. Saska and R. M. Scarel-Caminaga, Bacterial cellulose-hydroxyapatite composites with osteogenic growth peptide (OGP) or pentapeptide OGP on bone regeneration in critical-size calvarial defect model, J. Biomed. Mater. Res., Part A, 2015, 103(10), 3397-3406, DOI: 10.1002/jbm.a.35472.

50 Y. K. Jo, B. H. Choi, C. S. Kim and H. J. Cha, Diatom-Inspired Silica Nanostructure Coatings with Controllable Microroughness Using an Engineered Mussel Protein Glue to Accelerate Bone Growth on Titanium-Based Implants, Adv. Mater., 2017, 29(46), 1704906.

51 H. Liu, W. Li, B. Luo, X. Chen, W. Wen and C. Zhou, Icariin immobilized electrospinning poly(l-lactide) fibrous membranes via polydopamine adhesive coating with enhanced cytocompatibility and osteogenic activity, Mater. Sci. Eng., C, 2017, 79, 399.

52 H. J. Cho, S. K. Perikamana, J. H. Lee, J. Lee, K. M. Lee, C. S. Shin and H. Shin, Effective immobilization of BMP-2 mediated by polydopamine coating on biodegradable nanofibers for enhanced in vivo bone formation, ACS Appl. Mater. Interfaces, 2014, 6(14), 11225-11235, DOI: 10.1021/ am501391z.

53 E. Ko, K. Yang, J. Shin and S. W. Cho, Polydopamine-assisted osteoinductive peptide immobilization of polymer scaffolds for enhanced bone regeneration by human adipose-derived stem cells, Biomacromolecules, 2013, 14(9), 3202-3213, DOI: 10.1021/bm4008343.

54 W. Yang, X. Zhang, K. Wu, X. Liu, Y. Jiao and C. Zhou, Improving cytoactive of endothelial cell by introducing fibronectin to the surface of poly L-Lactic acid fiber mats via dopamine, Mater. Sci. Eng., C, 2016, 69, 373-379.

55 Z. Wang, L. Chen, Y. Wang, X. Chen and P. Zhang, Improved Cell Adhesion and Osteogenesis of op-HA/PLGA Composite by Poly(dopamine)-Assisted Immobilization of Collagen Mimetic Peptide and Osteogenic Growth Peptide, ACS Appl. Mater. Interfaces, 2016, 8(40), 26559-26569, DOI: 10.1021/ acsami.6b08733.

56 S. Zeng, J. Ye, Z. Cui, J. Si, Q. Wang, X. Wang, K. Peng and W. Chen, Surface biofunctionalization of threedimensional porous poly(lactic acid) scaffold using chitosan/OGP coating for bone tissue engineering, Mater. Sci. Eng., C, 2017, 77, 92-101, DOI: 10.1016/ j.msec.2017.03.220.

57 Q. Fei, C. Guo, X. Xu, J. Gao, J. Zhang, T. Chen and D. Cui, Osteogenic growth peptide enhances the proliferation of bone marrow mesenchymal stem cells from osteoprotegerin-deficient mice by CDK2/cyclin A, Acta Biochim. Biophys. Sin., 2010, 42(11), 801-806, DOI: 10.1093/ abbs/gmq086.

58 G. Kaur, M. T. Valarmathi, J. D. Potts, E. Jabbari, T. Saboattwood and W. Qian, Regulation of Osteogenic Differentiation of Rat Bone Marrow Stromal Cells on 2D Nanorod Substrates, Biomaterials, 2010, 31(7), 1732-1741.

59 K. Kim, D. Dean, A. Lu, A. G. Mikos and J. P. Fisher, Early osteogenic signal expression of rat bone marrow stromal cells is influenced by both hydroxyapatite nanoparticle content and initial cell seeding density in biodegradable nanocomposite scaffolds, Acta Biomater., 2011, 7(3), 12491264.

60 C. Xu, V. S. Thiruvadi, R. Whitmore and H. Liu, Delivery systems for biomedical applications: basic introduction, research frontiers and clinical translations, in Biomaterials in Translational Medicine, Elsevier, 2019, pp. 93-116.

61 N. G. Rim, S. J. Kim, Y. M. Shin, I. Jun, D. W. Lim, J. H. Park and H. Shin, Mussel-inspired surface modification of poly(Llactide) electrospun fibers for modulation of osteogenic differentiation of human mesenchymal stem cells, Colloids Surf., B, 2012, 91(3), 189-197.

62 E. Ko, K. Yang, J. Shin and S. W. Cho, Polydopamine-Assisted Osteoinductive Peptide Immobilization of Polymer Scaffolds for Enhanced Bone Regeneration by Human AdiposeDerived Stem Cells, Biomacromolecules, 2013, 14(9), 32023213.

63 S. Saska, L. N. Teixeira, L. M. S. de Castro Raucci, R. M. Scarel-Caminaga, L. P. Franchi, R. A. Dos Santos, S. H. Santagneli, M. V. Capela, P. T. de Oliveira, C. S. Takahashi, A. M. M. Gaspar, Y. Messaddeq, S. J. L. Ribeiro and R. Marchetto, Nanocellulose-collagenapatite composite associated with osteogenic growth peptide for bone regeneration, Int. J. Biol. Macromol., 2017, 103, 467-476, DOI: 10.1016/j.ijbiomac.2017.05.086.

64 N. M. Moore, N. J. Lin, N. D. Gallant and M. L. Becker, The use of immobilized osteogenic growth peptide on gradient substrates synthesized via click chemistry to enhance MC3T3-E1 osteoblast proliferation, Biomaterials, 2010, 31(7), 1604-1611, DOI: 10.1016/j.biomaterials.2009.11.011.

65 S. Saska, R. M. Scarel-Caminaga, L. N. Teixeira, L. P. Franchi, R. A. Dos Santos, A. M. Gaspar, P. T. de Oliveira, A. L. Rosa, C. S. Takahashi, Y. Messaddeq, S. J. Ribeiro and R. Marchetto, Characterization and in vitro evaluation of 
bacterial cellulose membranes functionalized with osteogenic growth peptide for bone tissue engineering, $J$. Mater. Sci.: Mater. Med., 2012, 23(9), 2253-2266, DOI: 10.1007/s10856-012-4676-5.

66 G. M. Policastro, F. Lin, L. A. Smith Callahan, A. Esterle, M. Graham, K. Sloan Stakleff and M. L. Becker, OGP Functionalized Phenylalanine-Based Poly(ester urea) for Enhancing Osteoinductive Potential of Human Mesenchymal Stem Cells, Biomacromolecules, 2015, 16(4), 1358-1371, DOI: 10.1021/acs.biomac.5b00153.

67 M. Lai, Z. Jin and Z. Su, Surface modification of $\mathrm{TiO}_{2}$ nanotubes with osteogenic growth peptide to enhance osteoblast differentiation, Mater. Sci. Eng., C, 2017, 73, 490-497, DOI: 10.1016/j.msec.2016.12.083.
68 K. S. Stakleff, F. Lin, L. A. Smith Callahan, M. B. Wade, A. Esterle, J. Miller, M. Graham and M. L. Becker, Resorbable, amino acid-based poly(ester urea)s crosslinked with osteogenic growth peptide with enhanced mechanical properties and bioactivity, Acta Biomater., 2013, 9(2), 51325142, DOI: 10.1016/j.actbio.2012.08.035.

69 J. M. Kanczler and R. O. C. Oreffo, Osteogenesis and angiogenesis: the potential for engineering bone, Eur. Cells Mater., 2008, 15, 100-114.

70 Q. Guo, C. Liu, J. Li, C. Zhu, H. Yang and B. Li, Gene expression modulation in TGF-beta3-mediated rabbit bone marrow stem cells using electrospun scaffolds of various stiffness, J. Cell. Mol. Med., 2015, 19(7), 1582-1592, DOI: 10.1111/jcmm.12533. 